\title{
Correction to A Framework for Identifying Reference Wetland Conditions in Highly Altered Landscapes
}

\author{
Marinus L. Otte ${ }^{1} \cdot$ Wei-Ta Fang ${ }^{2} \cdot$ Ming Jiang $^{3}$
}

Published online: 22 April 2021

(C) Society of Wetland Scientists 2021

\section{Correction to Wetlands (2021)}

https://doi.org/10.1007/s13157-021-01439-0

The authors wish to make the following clarification to their paper:

"When mentioning 'Taiwan' in the text, we are referring to Taiwan, China. When in the text we mention Taiwan and China separately, this is to emphasize the differences that exist in laws pertaining to wetlands between Taiwan and mainland China as relevant to the subject matter of our publication".

On behalf of the authors

Publisher's Note Springer Nature remains neutral with regard to jurisdictional claims in published maps and institutional affiliations.

The online version of the original article can be found at https://doi.org/ 10.1007/s13157-021-01439-0

Marinus L. Otte

marinus.otte@ndsu.edu

1 Wet Ecosystem Research Group, Biological Sciences, North Dakota State University, PO Box 6050, Dept. 2715, Fargo, ND 58108-6050, USA

2 Graduate Institute of Environmental Education, National Taiwan Normal University, 11677 Taipei, Taiwan

3 Key Laboratory of Wetland Ecology and Environment, Northeast Institute of Geography and Agroecology, Chinese Academy of Sciences, Changchun 130102, Jilin, China 